\title{
Associated Factors and Impacts of Social Phobia on Academic Performance among Students from the University of Parakou (UP)
}

\author{
Anselme Djidonou*, Francis Tognon Tchégnonsi, Thierry Adoukonou, \\ Iréti Nethania Elie Ataïgba, Chérifath Nawale Assa-Issa, Prosper Gandaho
}

Faculty of Medecine, University of Parakou, Parakou, Benin

Email: "cmpjubile2000@gmail.com

Received 21 February 2016; accepted 19 March 2016; published 22 March 2016

Copyright (C) 2016 by authors and Scientific Research Publishing Inc.

This work is licensed under the Creative Commons Attribution International License (CC BY). http://creativecommons.org/licenses/by/4.0/

\begin{abstract}
Background: Social phobia disrupts students in their academic career. The aim of this research work was to study this anxious disorder impact on the academic performance among students from the University of Parakou (UP). Study methods: It was a descriptive cross-sectional study with prospective data collection among 363 students recruited through systematic random sampling from April to June 2015 at the campus of the UP. A questionnaire including the Mini International Neuropsychiatric Interview (MINI), the Liebowitz social anxiety intensity evaluation scale and the ASSIST was used for data collection in compliance with recommended ethical principles. Results and Conclusion Social phobia prevalence among students from the campus of University of Parakou was 11. 6\% $\left[\mathrm{CI}_{95 \%}=10.9\right.$ - 21. 2]. Its intensity was moderate (66.7\%), medium (23.4\%), severe $(7.1 \%)$ and very severe $(4.8 \%)$ only among female students. Moreover, gender, rural or urban living environment and field of study were statistically associated with this social phobia which reduced academic performance by $\mathbf{5 7 . 1 \%}$, among the studied population. However, $42.9 \%$ were not influenced in any way. Addiction to alcoholic beverages (23.8\%) and anxiolytics (9.5\%) were used to overcome the disorder. Although the risk of dependency to these substances was low, adverse effects on their health and socio-professional future were to be taken seriously.
\end{abstract}

\section{Keywords}

Social Phobia, Students, Impacts, Academic Performance, UP/Benin

\footnotetext{
${ }^{*}$ Corresponding author.
}

How to cite this paper: Djidonou, A., Tchégnonsi, F.T., Adoukonou, T., Ataïgba, I.N.E., Assa-Issa, C.N. and Gandaho, P. (2016) Associated Factors and Impacts of Social Phobia on Academic Performance among Students from the University of Parakou (UP). Open Journal of Psychiatry, 6, 151-157. http://dx.doi.org/10.4236/ojpsych.2016.62018 


\section{Introduction}

Social phobia disorder was not noticed in the DSM III until 1980 [1]. This disorder is characterized by the fear of being exposed to others' observations, at the risk of acting in a humiliating or embarrassing manner. It is usually underpinned by the fear of being subjected to criticism from others and decline of self-esteem [2]. Although social phobia often sets up early in the life of a person between 14 and 24 years old, it is diagnosed quite later on because the subjects are ashamed of their weakness and fear the misunderstanding and the helplessness of their circle. The somatic manifestations of this anxiety usually amplify phobic fear by increasing the fear of shaking, urinating, or fainting in public. In addition, avoidance conducts are some usual consequence of phobic anxiety but mostly, that of anticipatory anxiety. This leads to the belief that any confrontation can only be catastrophic, thus playing the role of a real contributor to such disorder.

It is noteworthy that the prevalence of social phobia can significantly vary according to the criteria and questionnaires. For instance, in a DSM III criteria-based US study by the National Comorbidity Survey (NCS-R), Magee et al. [3] reported a 13.3\% prevalence of social phobia. Moreover, as for Kessler et al. [4], social phobia affected one out of eight people from the general population and lifetime prevalence was $8 \%$. In the European Study of the Epidemiology of Mental Disorders (ESEMeD) led by Lépine et al. [5], social phobia prevalence in France within the last twelve months and over lifetime was $1.7 \%$ and $4.7 \%$ respectively.

Students are familiar to the stress preceding written or oral examinations, oral presentations or simply the fact of speaking in class or among peers. That sort of anxiety compels restraint and undermines the efforts of students to express themselves within groups. As far as the socio-phobic students are concerned, this anxiety is excessive and may affect their academic performance. It may also cause addictions to psychoactive substances. In our societies, social phobia is known to exist although people have always disregarded it. The existence of little or no records about social phobia justifies our interest in this subject.

\section{Methods}

In this research work, a cross-sectional descriptive and analytical study was conducted from April to June 2015, focusing on students enrolled at the University of Parakou (UP) for the 2014-2015 academic year. However, evening class students as well as those who did not register before the survey had been excluded. A systematic sampling method by random sampling was used as follow: setting up a numbered list of students registered in each training and research college of UP, selecting colleges and years of study at random. At the end, seven faculties were selected. Then, a sampling interval was determined within each institution based on the ratio between the number of students of the institution and the corresponding sample size. The first student was chosen from a random number ranged from 1 and the total number of students. The following student was then selected by applying the sampling interval process until the size $(\mathrm{N})$ of the sample from the whole university is reached, using the Schwartz formula:

$$
\begin{aligned}
& N=\frac{Z \alpha^{2} p q}{i^{2}} \text { with } n=\text { minimum number of students to investigate } \\
& Z \alpha=(U \alpha) \\
& \alpha=\text { accepted error risk (5\%) } \\
& U \alpha=\text { difference limited to the risk } \alpha(1.96) \\
& p: \text { prevalence of studied phenomenon } \rightarrow p=4.3 \%[6] \\
& q=1 p=1-043=0.957 \\
& i=2.19 \% \text { (desired accuracy for our results) }
\end{aligned}
$$

A minimum number of students study $n=329.61$ with a margin of $10 \%$ helped to get a size of 362.57 , that is 363 students.

The dependent variable was the social phobia with the modality yes/no. As for the independent variables, they were related to socio-demographic and cultural characteristics, the behaviors of addiction to substances and the impacts of social phobia on academic performance. A questionnaire including the MINI [7] [8] for tracking social phobia among students, the Liebowitz's social phobia intensity rating scale for assessing the intensity of social phobia [9], and the Assessment Smoking and Substance Involvement Screening Test [10], to search for the use of psychoactive substances, was used for data collection by a team of seven students surveyors from the epidemiology school of UP in accordance with ethical principles contained in the World Medical Association's Declaration of Helsinki [11]. 
Data processing and analysis were conducted using the software EPI DATA 3.1fr and EPI info Version 7. Concerning qualitative variables, they were expressed in frequency with their confidence interval rated 95\%. Finally, Karl Pearson's khi-square test or Fischer's test was used for frequency comparison depending on the case, with a statistical significance threshold for $p$ less than $5 \%$.

\section{Results}

\subsection{Socio-Demographic Characteristics of Students}

The study population amounted to 363 students, consisting of 268 (73.83\%) male subjects with a sex-ratio of 2.82. The average age was $22.69 \pm 2.97$ years ranging from 16 to 42 years. Students in the age group 15 to 25 years accounted for $82.64 \%$. They belonged to the socio cultural group Fon and $41.6 \%$ of them were related; besides, $73 \%$ were Christians.

\subsection{Prevalence of Social Phobia}

Forty-two students out of the 363 surveyed were social-phobic. The prevalence of social phobia among students from the University of Parakou in 2015 was $11.6 \%$ [CI $\mathrm{I}_{95 \%}=10.9$ to 21.2]. The intensity of social phobia was as follow: Moderate 66.67\%, Medium 21.43\%, Severe 7.14\% and Very Severe 4.76\%.

\subsection{Factors Associated to Social Phobia among UP Students in 2015}

1) Gender and Age

Female students showed severe and very severe intensity of social phobia. That intensity varied significantly according to the gender $(p=0.01)$. Table 1 shows the prevalence of social phobia based on gender and age.

2) Social phobia, residence and living environment

3) Social phobia, field of education and year of study

In fact, students from agronomy faculty represented more than 6/33 (18.18\%) of socio-phobic population compared with other faculties. In other words, the intensity of social phobia varies significantly depending on the field of study $[p=0.02$ (Chi-squared $=31.77$, Degrees of freedom $=18$ )]. Based on this, we can say that socio-phobic of the first and second year had a severe social phobia with a statistically significant difference.

4) Social phobia and addiction to psychoactive substances

\subsection{Social Phobia (SP) Impacts on Academic Performance (AP)}

Academic performance of $57.14 \%$ of socio-phobic students were affected by social phobia.

\section{Discussion}

\subsection{Social Phobia Prevalence}

Considering the fact that we do not use the same data collection method, we often encounter great difficulty in

Table 1. Prevalence of social phobia according to gender and age ( $\mathrm{N}=363$; UP, 2015).

\begin{tabular}{|c|c|c|c|c|}
\hline & \multirow{2}{*}{ Total } & \multicolumn{2}{|c|}{ Social Phobia } & \multirow{2}{*}{$p$} \\
\hline & & $\mathbf{n}$ & $\%$ & \\
\hline \multicolumn{5}{|l|}{ Gender } \\
\hline Male & 268 & 25 & 9.32 & 0.03 \\
\hline Female & 95 & 17 & 17.89 & \\
\hline Total & 363 & 42 & 11.57 & \\
\hline \multicolumn{5}{|c|}{ Age (years) } \\
\hline $15-25$ & 300 & 35 & 11.70 & \\
\hline $25-35$ & 62 & 7 & 11.30 & 0.92 \\
\hline $35-45$ & 1 & 0 & 0.00 & \\
\hline Total & 363 & 42 & 11.60 & \\
\hline
\end{tabular}


comparing studies on social phobia. Besides, the types of criteria used made the comparison of the results from one study to another one extremely difficult. Then, it emerges from this study that the prevalence of social phobia was $11.6 \%$ [ $\mathrm{CI}_{95 \%}=10.9$ to 21.2] among students of Parakou University in 2015. In fact, this prevalence is lower than those found in Canada, Quebec and Switzerland [12]-[14], respectively 13.0\%; 13.0\% and 14.3\%. Moreover, a study on a series of Maudsney Hospital's phobic consultants, conducted by Marks [15] in 1970, noted a prevalence of $8 \%$ lower than that found in this study.

\subsection{Social Phobia, Gender and Age}

Twenty to two hundred sixty-eight (9.32\%) male students surveyed were socio-phobic against 17/95 (17.89\%) female students (see Table 1). Female subjects were suffering mainly from social phobia and this was confirmed by Berghändler et al. [14], Switzerland, in his report. All the same, an update in the treatment of anxiety disorders by Bernier et al. [13] found that social phobia would affect more women than men at a ratio of three women for every two men. On this point, social phobia in schools maintains psychological distress whose average score for female students $(13.45 \pm 5.50)$ is significantly more severe than that of male students (11.78 \pm 5.08) [16].

It appears from our study that the prevalence of social phobia was $11.7 \%$ for students aged 15 to $25,11.3 \%$ for those aged 25 to 35 and zero for those aged 35 to 45 . It seems therefore that students develop protective factors against the disorder as they get older and progress in their studies.

\subsection{Social Phobia and Living Environment}

As revealed previously, UP students living in rural areas were more socio-phobic than those living in urban areas (see Table 2). In other words, the prevalence of social phobia varied significantly depending on the type of environment $(p=0.03)$. On the one hand, $10.2 \%$ of 137 students living with their parents in Parakou were socio-phobic against $12.4 \%$ for those living far from their parents. On the other hand, those not living with their parents but rather with their brothers accounted 22.6\% of socio-phobic. Accordingly, the socio-phobic of the first and second year showed a severe social phobia with a statistically significant difference (see Table 3). In reality, these undergraduates seemed most vulnerable as they were entering a university world where they were forced to live far away from their parents for the first time [17]. Therefore, a comfortable social environment would be a protective factor against social phobia among students from the University of Parakou and also against the separation anxiety.

Table 2. Prevalence of social phobia based on residence and living environment, (N = 363; UP, 2015).

\begin{tabular}{|c|c|c|c|c|}
\hline & \multirow{2}{*}{ Total } & \multicolumn{2}{|c|}{ Social Phobia } & \multirow{2}{*}{$\mathrm{p}$} \\
\hline & & $\mathrm{n}$ & $\%$ & \\
\hline \multicolumn{5}{|l|}{ Residence } \\
\hline Rural & 69 & 13 & 18.8 & 0.03 \\
\hline Urban & 294 & 29 & 09.9 & \\
\hline \multicolumn{5}{|l|}{ Living environment } \\
\hline Living with parents & 137 & 14 & 10.2 & \\
\hline Monogamous & 81 & 8 & 9.9 & 0.79 \\
\hline Polygamous & 37 & 5 & 13.5 & \\
\hline Single-parent & 17 & 1 & 5.9 & \\
\hline Stepfamily & 2 & 0 & 0.0 & \\
\hline Not living with parents & 226 & 28 & 12.4 & \\
\hline Alone & 112 & 10 & 8.9 & \\
\hline With brother/sister & 53 & 12 & 22.6 & 0.04 \\
\hline With a friend & 38 & 4 & 10.5 & \\
\hline Others & 23 & 1 & 4.3 & \\
\hline
\end{tabular}


Table 3. Distribution of socio phobic-students based on year of study and intensity of social phobia ( $\mathrm{N}=363$; UP, 2015).

\begin{tabular}{cccccc}
\hline \multirow{2}{*}{ Year of study } & \multicolumn{5}{c}{ Intensity of social phobia } \\
\cline { 2 - 5 } & Moderate & Medium & Severe & Very Severe & Total \\
\hline $1^{\text {st }}$ Year & 7 & 4 & 1 & 1 & 13 \\
$2^{\text {nd }}$ year & 11 & 2 & 0 & 1 & 14 \\
$3^{\text {rd }}$ Year & 2 & 0 & 1 & 0 & 3 \\
$4^{\text {th }}$ Year & 2 & 0 & 0 & 0 & 2 \\
$5^{\text {th }}$ Year & 1 & 1 & 0 & 0 & 2 \\
$6^{\text {th }}$ Year & 5 & 1 & 1 & 0 & 7 \\
$7^{\text {th }}$ Year & 0 & 1 & 0 & 0 & 1 \\
Total & 28 & 9 & 3 & 2 & 42 \\
\hline
\end{tabular}

Chi-squared $=31.89$; Degrees of freedom $=18 ; p=0.02$

Table 4. Distribution of socio-phobic students based on alcohol addiction and risk of dependency $(\mathrm{N}=363$; UP, 2015).

\begin{tabular}{|c|c|c|}
\hline & Number (n) & Frequency \\
\hline \multicolumn{3}{|c|}{ Addiction to Alcoholic Beverages } \\
\hline Yes & 10 & 23.8 \\
\hline No & 32 & 76.2 \\
\hline Total & 42 & 100.0 \\
\hline \multicolumn{3}{|c|}{ Dependency Risk } \\
\hline Moderate & 10 & 100.0 \\
\hline Medium & 0 & 0.0 \\
\hline Severe & 0 & 0.0 \\
\hline Total & 10 & 100.0 \\
\hline \multicolumn{3}{|c|}{ Addiction to Anxiolitics } \\
\hline Yes & 4 & 9.5 \\
\hline No & 38 & 90.5 \\
\hline Total & 42 & 100.0 \\
\hline \multicolumn{3}{|c|}{ Dependency Risk } \\
\hline Moderate & 4 & 100.0 \\
\hline Medium & 0 & 0.0 \\
\hline Severe & 0 & 0.0 \\
\hline Total & 4 & 100.0 \\
\hline
\end{tabular}

\subsection{Social Phobia among Students from UP and Psychoactive Substances Consumption}

As mentioned above, some socio-phobic students would drink alcohol to manage their disorder while others would rather go for anxiolytics (see Table 4). Indeed, alcohol and anxiolytics were used respectively by $23.8 \%$ and 9.5\% socio-phobic students and Grebot et al. [18] reported that $35 \%$ to $45 \%$ of these students would use sleep as solution while $13 \%$ would rather use alcohol, drugs or other toxic substances. Hence, access to university is a rite of stressful passage causing dysfunctional adjustment strategies for $1^{\text {st }}$ and $2^{\text {nd }}$ year students. Moreover, they use psychoactive substances as anxiolytic, which is an inadequate anti-phobia behavior. Then, the existence of a dependency risk, yet low, doesn’t always immune from cognitive and behavioral damage.

\subsection{Social Phobia and Academic Performance}

Referring to what has been said so far, social phobia affects the academic performance of $57.14 \%$ of Parakou University students showing this disorder (see Table 5); it induces a decline in academic performance among such students. According to Delgado et al. [19], adolescents with social anxiety unlike those without social an- 
Table 5. Distribution of socio-phobic students: impact of social phobia (SP) on academic performance (AP) and therapeutic remedy ( $\mathrm{N}=363$; UP, 2015).

\begin{tabular}{|ccc|}
\hline & Number (n) & Frequency (\%) \\
\hline Social phobia impact on academic performance & & \\
\hline Yes & 24 & 57.14 \\
No & 18 & 42.86 \\
\hline Type of impact & 42 & 100.00 \\
\hline Improves the results & & \\
Worsens the results & 0 & 0.00 \\
Total & 24 & 100.00 \\
\hline Therapeutic remedy & 24 & 100.00 \\
\hline Yes & & \\
No & 5 & 11.90 \\
Total & 37 & 88.10 \\
\hline & 42 & 100.00 \\
\hline
\end{tabular}

xiety, consider themselves less socially competent and present a low-level self-esteem. Also, the progress of the disorder is chronic and characterized by a significant professional impact frequency which is very disabling. As a result, the repeated failures it causes can induce depression whose suicidal risk is considered to be present in about $40 \%$ of socio-phobic [20].

\section{Conclusion}

In a nutshell, it emerges from this study that many students from Parakou University Campus suffer from social phobia. Furthermore, this is predominant among female subjects and is often a breeding ground for other pathologies such as addiction to psychoactive substances to set up. All the same, it affects students' academic performance. Finally, this anxiety disorder deserves to be spotted as systematically as possible so as to refer students to specific therapeutic remedies.

\section{Conflicts of Interest}

None.

\section{References}

[1] Pélissolo, A. and Lépine, J.P. (1995) Les phobies sociales: Perspectives historiques et conceptuelles. L’Encéphale, 21, 15-24.

[2] Strenna, L., Chahraoui, K. and Vinay, A. (2009) Santé psychique chez les étudiants de première année d'école supérieure de commerce: Liens avec le stress de l'orientation professionnelle, l'estime de soi et le coping. L'orientation Scolaire et Professionnelle, 38/2, 183-204. http://dx.doi.org/10.4000/osp.1902

[3] Magee, W.J., Eaton, W.W., Wittchen, H.U., McGonagle, K.A. and Kessler, R.C. (1996) Agoraphobia, Simple Phobia, and Social Phobia in the National Comorbidity Survey. Archives of General Psychiatry, 53, 159-168. http://dx.doi.org/10.1001/archpsyc.1996.01830020077009

[4] Kessler, R.C., Stein, M.B. and Berglund, P. (1998) Social Phobia Subtypes in the National Comorbidity Survey. American Journal of Psychiatry, 155, 613-619. http://dx.doi.org/10.1176/ajp.155.5.613

[5] Lépine, J.P., Gasquet, I., Kovess, V., Arbabzadeh-Bouchez, S., Nègre-Pagès, L., Nachbaur, G. and Gaudin, A.F. (2005) Prévalence et comorbidité des troubles psychiatriques dans la population générale française: Résultats de l'étude épidémiologique ESEMeD/MHEDEA 2000/(ESEMeD). L’Encéphale, 31, 182-194. http://dx.doi.org/10.1016/S0013-7006(05)82385-1

[6] Roelandt, J., Caria, A. and Anguis, M. (2004) Présentation de l'enquête Santé mentale en population générale (SMPG).

[7] Lecrubier, Y., Sheehan, D., Hergueta, T. and Weiller, E. (1998) The Mini International Neuropsychiatric Interview. European Psychiatry, 13, 198s-198s. http://dx.doi.org/10.1016/S0924-9338(99)80239-9 
[8] Philipps, V., Amieva, H., Andrieu, S., Dufouil, C., Berr, C., Dartigues, J. F., Proust-Lima, C., et al. (2014) Normalized Mini-Mental State Examination for Assessing Cognitive Change in Population-Based Brain Aging Studies. Neuroepidemiology, 43, 15-25. http://dx.doi.org/10.1159/000365637

[9] Yao, S.N., Note, I., Fanget, F., Albuisson, E., Bouvard, M., Jalenques, I. And Cottraux, J. (1999) L’anxiété sociale chez les phobiques sociaux: Valiation de l'échelle d'anxiété sociale de Liebowitz (version Francaise). L’Encéphale: Revue de psychiatrie clinique biologique et thérapeutique.

[10] Humeniuk, R., Ali, R., Babor, T.F., Farrell, M., Formigoni, M.L., Jittiwutikarn, J., Nhiwatiwa, S., et al. (2008) Validation of the Alcohol, Smoking and Substance Involvement Screening Test (ASSIST). Addiction, 103, 1039-1047. http://dx.doi.org/10.1111/j.1360-0443.2007.02114.x

[11] World Medical Association (2015) Declaration of Helsinki, 2013. WMA Declaration of Helsinki-Ethical Principles for Medical Research Involving Human Subjects.

[12] Cara Katz, B.S., Murray, B., Stein, M.D. and Jitender Sareen, M.D. (2013) Les troubles anxieux dans le DSM-5: Nouvelles règles sur le diagnostic et le traitement. Une ressource éducative pour les médecins de l'Association Canadienne pour les troubles anxieux et de l'humeur. Conférences Scientifiques, 2, 1-6.

[13] Bernier, J.P. and Simard, I. (2007) Mise à jour dans le traitement des troubles anxieux. Pharmactuel, 40, $204-217$.

[14] Berghändler, T., Stieglitz, R.D. and Vriends, N. (2007) La phobie sociale: Etiologie, diagnostic et traitement. Forum Med Suisse, 7, 225-230.

[15] Marks, I.M. (1970) The Classification of Phobic Disorders. The British Journal of Psychiatry, 116, 377-386. http://dx.doi.org/10.1192/bjp.116.533.377

[16] Spitz, E., Costantini, M.L. and Baumann, M. (2007) Détresse psychologique et stratégies de coping des étudiants en première année universitaire. Revue Francophone du Stress et du Trauma, 7, 217-225.

[17] Réveillère, C., Nandrino, J.L., Sailly, F., Mercier, C. And Moreel, V. (2001) Etude des tracas quotidiens des étudiants: liens avec la sante perçue. Annales Medico-Psychologiques, 6, 460-465. http://dx.doi.org/10.1016/S0003-4487(01)00070-1

[18] Grebot, E. and Barumandzadeh, T. (2005) L'accès à l'Université: une situation stressante à l'origine de certaines stratégies d'ajustement dysfonctionnelles. Annales Médico-Psychologiques, Revue Psychiatrique, 163, 561-567.

[19] Delgado, B., Candido, J.I., Garcia-Fernandez, J.M., Hugon, M., Soledad-Torregrosa, M. and del Carmen Martinez-Monteagudo, M. (2013) Concept de soi social et estime de soi chez les élèves espagnols ayant de l'anxiété sociale. 6ème Colloque international du RIPSYDEVE, Actualités de la Psychologie du Développement et de l'Éducation, 366-374.

[20] Pélissolo, A., Huron, C., Fanget, F., Servant, D., Stiti, S., Richard-Berthe, C. and Boyer, P. (2006) Les phobies sociales en psychiatrie: Caractéristiques cliniques et modalités de prise en charge (étude Phoenix). L'Encéphale, 32, 106-112. http://dx.doi.org/10.1016/S0013-7006(06)76143-7 